\title{
Optimization of Cyan flexo dye removal by nano zero-valent iron using response surface methodology
}

\begin{abstract}
Application of nano zero-valent iron ( $n Z V I)$ as a catalyst in a decolorization process is a simple and sensitive method for Cyan flexo dye removal from the aqueous solution. In this paper, a central composite design (CCD), under the response surface methodology (RSM), was applied in order to optimize experimental conditions of the Cyan removal from aqueous solution. The influence of four independent variables was studied: $n Z V I$ dosage (5-45 mg L $\mathrm{L}^{-1}$ ), initial dye concentration (2-14 $\left.\mathrm{g} \mathrm{L}^{-1}\right), \mathrm{pH}(2-10)$ and removal time (20-100 $\mathrm{min})$, in order to build second order quadratic model and to predict the responses. The highest removal percent of $96.35 \%$ was attained, and the optimum parameters are achieved after $1 \mathrm{~h} / 24 \mathrm{~h}$ precipitation: $n Z \mathrm{VI}$ dosage (5/45 $\left.\mathrm{mg} \mathrm{L}^{-1}\right)$, initial dye concentration (2/14 $\left.\mathrm{g} \mathrm{L}^{-1}\right)$, removal time (20/100 $\mathrm{min}$ ) and $\mathrm{pH}(2 / 10)$. The Cyan removal efficiency of $38 \%$ and $62 \%$ were estimated under optimized experimental conditions.
\end{abstract}

\section{KEY WORDS}

cyan flexo dye, nano zero valent iron, decolorization, response surface methodology, optimization process

\author{
Vesna Kecić ${ }^{1}$, Đurđa \\ Kerkez ${ }^{2}$, Miljana Prica ${ }^{1}$, \\ Sanja Rapajićs ${ }^{3}$ Anita \\ Leovac Maćerak², \\ Milena Bečelić-Tomin², \\ Dragana Tomašević \\ Pilipović
}

\author{
${ }^{1}$ University of Novi Sad, Faculty of \\ Technical Sciences, Department of \\ Graphic Engineering and Design, \\ Novi Sad, Serbia \\ ${ }^{2}$ University of Novi Sad, Faculty \\ of Sciences, Department of \\ Chemistry, Biochemistry and \\ Environmental Protection, \\ Novi Sad, Serbia \\ ${ }^{3}$ University of Novi Sad, Faculty \\ of Sciences, Department of \\ Mathematics and Informatics, \\ Novi Sad, Serbia
}

Corresponding author: Vesna Kecić e-mail:kecic@uns.ac.rs

First recieved: 07.09.2017. Accepted: 02.10.2017.

\section{Introduction}

Due to the rapid development and complexity of the technological printing production, waste management presents a key environmental issue for printers, in order to improve environmental performances. Prevention, as the first rule of hierarchy within sustainable development, is not always possible to comply, and therefore it is necessary to perform adequate recycling and disposal of printing waste products (Andrade et al., 2012; Adamović et al., 2014). Wastewaters discharged from printing operations may contain waste dye, cleanup solvents, photographic chemicals, acids, alkalis, lubricating oils, as well as metals such as silver, iron, chromium, copper and barium. Due to the lack of adequate effluents treatment, significant amount of potentially contaminated waste with inorganic and organic pollutants is often discharged directly into the sewage system. Managing and reducing the environmental impact of printing dyes has been an important feature over many years, and continues to be an on-going element of product and process development (Wu and Wang, 2012; Kiurski et al, 2016).

Printing dyes consist in four primary components: varnish, solvent, pigment and additives, each presenting their own unique environmental hazards and challenges. 
Flexographic printing process combine water-soluble and solvent-based dyes, which are primarily used in the printing of packaging materials (cardboard boxes, corrugated cardboard, paper bags and plastic bags, food packaging, newspapers, catalogues, etc). The colored dye effluent discharged from flexographic process, contains significant level of organic contaminants, which are known to be carcinogenic and toxic in nature, and therefore poses a big threat to the environment (Mijin, 2012).

Typically, dye wastewater is treated by using various physio-chemical methods, such as coagulation and flocculation, aerobic or anaerobic treatment, electrochemical treatment, membrane filtration, as well as adsorption methods. However, it is necessary to find alternative, eco-friendly and economically viable methods which are effective in dye removal process from large volumes of effluents (El Haddad et al., 2012; Asfaram et al., 2015; Elhalil et al., 2016; de Sales et al., 2013; Saad et al., 2017; Rasouli et al., 2017).

In recent years, usage of nZVI particles become an increasingly popular treatment of hazardous and toxic wastes, with great prominence for applications in environmental remediation. Studies have shown that a large number of pollutants like chlorinated organic compounds, nitroaromatic compounds, arsenic, heavy metals, pesticides, nitrate, dyes and phenol can be successfully treated from various media, with nZVI particles as a strong reducing agent (Kerkez et al., 2014; Yari et al., 2015; Poguberović et al., 2016; Khan et al., 2013). The type of removal mechanisms varies based on the contaminants and may involve processes like oxidation/ reduction, surface complexation, surface precipitation, and co-precipitation. The reaction processes occurring at the iron surface are strongly influenced by a number of factors, namely the nZVI chemical properties and structure, the presence of more than one contaminant species, as well as the hydrochemistry of the aqueous environment- $\mathrm{pH}$, redox and natural dissolved species (Poguberović, 2016).

Because of its characteristics, small particle size (1-100 $\mathrm{nm})$, large specific surface area with great intrinsic reactivity, high density, stronger adsorption properties and better mobility than bulk or micro scale iron particles, the $\mathrm{nZVI}$ technology become promising approach for treating dyes wastewater. Several studies have described dye removal process from various industrial wastewaters, where textile industry presents the most investigated one (Raman and Kanmani, 2016; Dutta et al., 2015; Nayana and Pushpa, 2016; Poursaberi et al., 2012). Group of authors (Satapanajaru et al., 2011; Rakhshaee, 2011 and Zong Shan et al, 2008) demonstrated that anionic dyes, such as Reactive black 5, Reactive red 198, Light green, Acid orange 7, Acid orange 8 and Sunset yellow can successfully be removed with up to $97 \%$ efficiency from the textile dye wastewater. Despite mentioned facts, there is a great lack within the data obtained from printing industry, which requires detailed investigation in the field of printing wastewater remediation.

Regardless mentioned advantages, nZVI particles are distinguished with some disadvantages, such as lack of stability, high tendency to agglomerate, secondary iron pollution and recovery of the fine nZVI particles after utilization. In order to overcome these issues, various stabilization methods have been developed to facilitate the usage of modified nZVI particles, where green synthesis deserves the most attention. This environmentally friendly, so-called "green" nZVI synthesis method uses natural plant extracts where the active substances, such as polyphenol are highly reductive compounds. The obtained extracts have high reductive capacities and assure the reduction of iron(III)/(II), producing $n Z V I$ particles (Saif et al., 2016; Zou et al., 2016). In this work, oak leaves were used to produce nZVI particles, and the extraction procedure is explained more detailed in experimental part.

In order to determine the optimum experimental conditions, as well as the effect of various operational parameters, including the nZVI dosage, initial dye concentration, $\mathrm{pH}$ value and removal time, on Cyan dye aqueous solution decolorization, RSM followed with CCD was applied. By selecting the RSM as an effective statistical and mathematical approach, in order to recognize the efficiency of an experimental system, various parameters were simultaneously appraised with a minimum number of experiments.

Therefore, present study investigates the application of $\mathrm{nZVI}$ nanoparticles under various operating conditions for the efficient removal of flexographic water-based Cyan dye from aqueous solution, optimized by using CCD under RSM.

\section{Experimental}

\section{Materials and chemicals}

Flexo dye wastewater is generated during the cleaning process of dye delivery and storage systems, as well as dye shipping containers. Given the fact that after the printing process wastewater is enriched with colorants (pigments and dyes), alkali-soluble, emulsions or colloidal dispersion chemistries, auxiliary solvents (alcohols, glycols and glycol ethers) and additives (waxes, plasticizers and defoamers), the purification process of printing wastewater is required, in order to meet increasingly stringent environmental quality standards.

A sample of wastewater from one flexographic printing facility located in Novi Sad, Serbia was analyzed in order to determine the concentrations of printing dye. All sample analyzes were carried out directly without special pre-treatment, whereas the chemicals used 
during the laboratory tests were analytically pure, used as received, without further purification. The laboratory tests were carried out using flexographic water-based Cyan dye, which contains cooper phthalocyanine chromophore (Figure 1), supplied by Flint Group. Properties of the Cyan dye are presented in Table 1.

\section{Table 1}

Properties of the Cyan dye

\begin{tabular}{l|l}
\hline Color Index Number & PB15:3 \\
\hline CAS number & $147-14-8$ \\
\hline Chemical formula & $\mathrm{C}_{32} \mathrm{H}_{16} \mathrm{CuN}_{8}$ \\
\hline Molecular weight [g mol $\left.{ }^{-1}\right]$ & 576.07 \\
\hline Maximum wavelength- $\lambda_{\text {max }}[\mathrm{nm}]$ & 636 \\
\hline
\end{tabular}

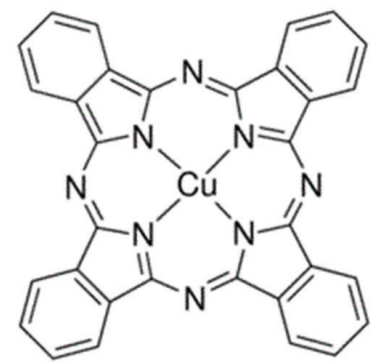

» Figure 1: Chemical structure of Cyan dye chromophore

\section{Determination of Cyan dye concentration in wastewater sample}

In order to evaluate Cyan dye concentration in the wastewater sample, the calibration curve method was performed (Figure 2). The absorbence of Cyan dye solutions was measured by UV/VIS spectrophotometer at $\lambda_{\text {max }}$ of $636 \mathrm{~nm}$ (UV 1800 Shimadzu).

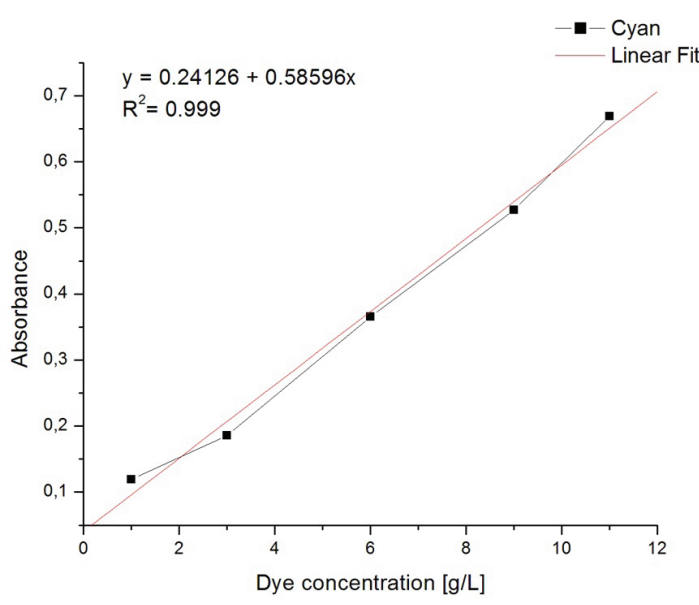

» Figure 2: Calibration curve of Cyan dye
working solution

The calibration curve indicated a dye concentration of $9.76 \mathrm{~g} \mathrm{~L}^{-1}$ in the wastewater sample. The obtained results were further used for experimental design in terms of choosing the initial dye concentration range.

\section{Synthesis and characterization of nZVI nanoparticles}

nZVI particles were prepared by "green" method, using oak leaves collected from oak trees (Quercus Peatrea) growing in the National Park of Fruška Gora, in Vojvodina, Serbia. Grinded oak leaves were penetrated through a sieve with a $2 \mathrm{~mm}$ pore size, and material up to $2 \mathrm{~mm}$ size was dried at $50^{\circ} \mathrm{C}$ during 48 hours in a dry oven. The extract of Quercus Peatrea was prepared by boiling $37 \mathrm{~g}$ of dried oak leaves with $1000 \mathrm{ml}$ of deionized water at $80^{\circ} \mathrm{C}$ for 20 min on a magnetic stirrer. After precipitation, the extracts were filtered by Büchner Vacuum Filtration Funnel. Furthermore, $\mathrm{Fe}$ (III) solution in a volume ratio of 1:3 was added in the extract. Mixture colors turned from yellow to dark brown, indicating the formation of nano particles. In that way, a $\mathrm{Fe}(0)$ concentration of $1.395 \mathrm{~g} \mathrm{~L}^{-1}$ in synthetized nanomaterial was obtained (Machado et al., 2013).

Standard methods like transmission electron microscopy (TEM; Philips CM 10) and scanning electron microscope analyses (SEM; Hithchi S-4700 Type II) were used to evaluate the morphology, size and nZVI particles distribution. Due to dispersive and stabilizing characteristics of oak leaves, it was confirmed a formation process of nanosize zero-valent iron particles with a spherical shape and non-agglomerated size of $10-30 \mathrm{~nm}$. The available specific surface, as well as nanoparticles size, can have a great influence on the number of reactive sites available for binding the targeted pollutants. The performed characterization confirmed the possible usage of oak leaf extracts for "green" nZVI synthesis (Poguberović et al., 2016).

\section{Experimental Design}

As an empirical statistical method, RSM uses quantitative data of appropriately designed experiments in order to determine the regression model and optimal operating conditions. The main objective of RSM is to simultaneously optimize the levels of variables, in order to attain the best system performance and to determine the optimal variables of the examined process (Saad et al., 2017).

Before applying the RSM, it is necessary to choose an experimental design that will define which experiments should be carried out in the studied experimental region. For that purpose, experimental matrix CCD can be performed. CCD is the appropriate model for fitting a quadratic surface, which gives good results and requires a minimum number of experiments for the implementation. Based on the CCD analysis, it is possible to evaluate the cumulative effect of the process parameters of independent variables on the output variable process, but also to examine the individual impact of the investigated factors. A linear, square or cubic effect of tested variables can be tested. The 
efficiency of the CCD method in experimental process optimization is reflected within significant reduction of set experiments (Markandeya et al., 2017).

In this study, the RSM was used in order to conduct experimental design and process optimization, which was influenced by four independent variables. Nanomaterial dosage $\left(X_{1}\right)$, initial dye concentration $\left(X_{2}\right), p H$ value $\left(X_{3}\right)$ and removal time $\left(X_{4}\right)$ are defined as four independent variables, where their influence on the dependent variable (decolorization efficiency) was investigated. Software Wolfram Mathematica 8 was used to generate the experimental matrix, by using the CCD. The total number of required experiments was calculated based on the equation 1 (Logman et al., 2016; Asfaram et al., 2015):

$\mathrm{N}=2^{\mathrm{k}}+2 \mathrm{k}+\mathrm{Cp}$

where $N$ represent number of experiments, $k$ is the number of variables, and $C p$ is the number of central points.

The experimental design for testing the decolorization efficiency of Cyan dye solution is presented in Table 2.

Table 2

CCD matrix

\begin{tabular}{c|c|c|c|c|c|c}
\hline StdOrder & RunOrder & PtType & $\begin{array}{c}\mathbf{n Z V I} \\
\text { [mg L-1 }\end{array}$ & $\begin{array}{c}\text { Dye } \\
\text { [g L-1 }\end{array}$ & $\mathbf{p H}$ & $\mathbf{t}[\mathbf{m i n}]$ \\
\hline 20 & 1 & -1 & 25 & 14 & 6 & 60 \\
\hline 28 & 2 & 0 & 25 & 8 & 6 & 60 \\
\hline 6 & 3 & 1 & 35 & 5 & 8 & 40 \\
\hline 3 & 4 & 1 & 15 & 11 & 4 & 40 \\
\hline 7 & 5 & 1 & 15 & 11 & 8 & 40 \\
\hline 27 & 6 & 0 & 25 & 8 & 6 & 60 \\
\hline 17 & 7 & -1 & 5 & 8 & 6 & 60 \\
\hline 4 & 8 & 1 & 35 & 11 & 4 & 40 \\
\hline 12 & 9 & 1 & 35 & 11 & 4 & 80 \\
\hline 21 & 10 & -1 & 25 & 8 & 2 & 60 \\
\hline 2 & 11 & 1 & 35 & 5 & 4 & 40 \\
\hline 18 & 12 & -1 & 45 & 8 & 6 & 60 \\
\hline 24 & 13 & -1 & 25 & 8 & 6 & 100 \\
\hline 13 & 14 & 1 & 15 & 5 & 8 & 80 \\
\hline 8 & 15 & 1 & 35 & 11 & 8 & 40 \\
\hline 22 & 16 & -1 & 25 & 8 & 10 & 60 \\
\hline 14 & 17 & 1 & 35 & 5 & 8 & 80 \\
\hline 19 & 18 & -1 & 25 & 2 & 6 & 60 \\
\hline 11 & 19 & 1 & 15 & 11 & 4 & 80 \\
\hline 16 & 20 & 1 & 35 & 11 & 8 & 80 \\
\hline 23 & 21 & -1 & 25 & 8 & 6 & 20 \\
\hline 15 & 22 & 1 & 15 & 11 & 8 & 80 \\
\hline 9 & 23 & 1 & 15 & 5 & 4 & 80 \\
\hline 10 & 24 & 1 & 35 & 5 & 4 & 80 \\
\hline 1 & 25 & 1 & 15 & 5 & 4 & 40 \\
\hline 29 & 26 & 0 & 25 & 8 & 6 & 60 \\
\hline 26 & 27 & 0 & 25 & 8 & 6 & 60 \\
\hline 5 & 28 & 1 & 15 & 5 & 8 & 40 \\
\hline 25 & 29 & 0 & 25 & 8 & 6 & 60 \\
\hline & & & & & & \\
\hline
\end{tabular}

\section{Catalytic activity of nZVI particles in decolorization process}

The decolorization experiments of Cyan dye aqueous solution were carried out in a batch mode and conducted in accordance with the factorial design described (Table 3). For each $250 \mathrm{~mL}$ of dye solution within known concentrations (5-14 $\left.\mathrm{g} \mathrm{L}^{-1}\right)$ and $\mathrm{pH}$ adjusted with $0.1 \mathrm{M}$ $\mathrm{CCH}_{2} \mathrm{SO}_{4}$ or $0.1 \mathrm{M} \mathrm{ccNaOH}$, predetermined quantities were placed in $1000 \mathrm{~mL}$ glass flask, and specific nZVI dosage (5- $45 \mathrm{mg} \mathrm{L}^{-1}$ ) was added. The mixture was kept under agitation at $120 \mathrm{rpm}$ at JAR aparatus (FC6S Velp scientific, Italy) within the temperature of $25^{\circ} \mathrm{C}$ for established reaction time (20-100 min). Decolorization efficiency was determined by measuring the absorbance of the aqueous solutions at $636 \mathrm{~nm}$ by using UV/VIS spectrophotometer, within the equation (2):

$E(\%)=A_{0}-A / A_{0} * 100$

where $A_{o}$ is absorbance of Cyan dye aqueous solution without nanomaterial, whereas $A$ represents absorbance of Cyan dye aqueous solution with nanomaterial. Absorbance measurements were conducted after 1-hour and 24-hour precipitation, in order to compare and distinguish aqueous solution decolorization, due to binding of dye particles to the nanomaterial surface.

\section{Results and Discussion}

\section{Process optimization}

Determination of optimal conditions requires implementation of a large number of experiments with understanding the role of each investigated parameter. Experiments of decolorization efficiency can be influenced by a great number of factors, whereas in this paper the dye removal was promoted by the influence of nanomaterial dosage, initial dye concentration, $\mathrm{pH}$ value and removal time.

In recent published papers, it has been determined that nanomaterial concentration plays a significant role, since it affects the change in the molar ratio of nano zerovalent iron and pollutants in the medium. Yari et al. (2015) has determined that an increase of nZVI dosage contributes to the higher percentage removal of the pollutants, which may be attributed to the exposure of available surface sites necessary for the dye removal. On the other hand, Sohrabi et al. (2016) have determined that there is a possible limitation of the iron particle catalytic concentration, beyond which the reaction no longer occurs, or the reaction becomes significantly slower. However, the hypothesis of optimal nanomaterial dosage application is of great importance, because one of the main disadvantages in dye degradation process is a formation of a certain 
quantity of residual sludge, which has a negative impact on the environment and requires further treatment.

Beside nanomaterial dosage, $\mathrm{pH}$ value also affects the stability of the material and sorption capacity. The $\mathrm{pH}$ value greatly affects the redox reactions that occur on the surface of $\mathrm{nZVI}$, through the corrosion acceleration at low $\mathrm{pH}$ values and the passivation of the iron surface at high $\mathrm{pH}$, until the formation of iron hydroxide (O'Carroll et al., 2013; Poguberović, 2016). Studies have shown that the acidic medium with a $\mathrm{pH}$ range of 2- 4 is preferred for removing the dye particles from the aqueous solution (Raman and Kanmani, 2016; Nayana and Pushpa, 2016; Zong Shan et al, 2008).

The studies also found that the increase of dye concentration in aqueous solution and shorter reaction time decreases the decolorization efficiency, which is justified by the fact that the process of dye removal within these conditions is not finalized.

Optimization of process conditions was conducted under the limits of the tested variables: $5 \leq x_{1} \leq 45 ; 2 \leq x_{2} \leq 14$, $2 \leq x_{3} \leq 10,20 \leq x_{4} \leq 100$. The obtained results indicate that the maximum decolorization function for $1 \mathrm{~h}$ precipitation is achieved under the following conditions: $5 \mathrm{mg} \mathrm{L}^{-1}$ of $\mathrm{nZVI}, 2 \mathrm{~g} \mathrm{~L}^{-1}$ of dye, $\mathrm{pH}=2$ and reaction time of $20 \mathrm{~min}$. On the other hand, after $24 \mathrm{~h}$ precipitation, maximum decolorization efficiency was achieved within $45 \mathrm{mg} \mathrm{L}^{-1}$ of $\mathrm{nZVI}, 14 \mathrm{~g} \mathrm{~L}^{-1}$ of dye, $\mathrm{pH}$ value 10 and reaction time of $100 \mathrm{~min}$. Under these conditions, decolorization efficiency of Cyan dye aqueous solution was 38\% in the case of $1 \mathrm{~h}$ precipitation and $62 \%$ after $24 \mathrm{~h}$ precipitation.

\section{RSM analysis}

RSM and CCD are used with the aim to optimize the process condition, and to determine the effect of investigated parameters on the dye removal from the Cyan flexo aqueous solution. The obtained values of decolorization efficiency (\%) of the Cyan aqueous solution after $1 \mathrm{~h}$ and $24 \mathrm{~h}$ precipitation are presented in Table 3. Decolorization efficiency varied in the range of 1.58-74.10\% and $2.26-96.35 \%$, respectively, whereby a better dye removal was established after a longer precipitation period.

The relationship between the investigate variables (nanomaterial dosage, dye concentration, $\mathrm{pH}$ value and removal time) and decolorization efficiency is described using second-order polynomials. Experimental data are fitted through a quadratic model, where $Y$ presents the percentage of dye removal from the aqueous solution, while $X_{1}, X_{2}, X_{3}$ and $X_{4}$ are related to the nanomaterial dosage $\left(\mathrm{mg} \mathrm{L}^{-1}\right)$, dye concentration $\left(\mathrm{g} \mathrm{L}^{-1}\right), \mathrm{pH}$ and removal time ( $\mathrm{min}$ ), respectively. Equations 3 and 4 represent an evaluation of the process parameters impact for dye removal after $1 \mathrm{~h}$ and $24 \mathrm{~h}$ precipitation.
$Y=378,892-3,8708 x_{1}+0,001545 x_{1}^{2}-19,1976 x_{2}-$ $0,000291 x_{1} x_{2}+0,49425 x_{2}^{2}-26,2001 x_{3}+0,25868 x_{1} x_{3}$ $+0,90145 x_{2} x_{3}-0,59291 x_{3}^{2}-4,9501 x_{4}+0,03723 x_{1} x_{4}+$ $0,08366 x_{2} x_{4}+0,27000 x_{3} x_{4}+0,01498 x_{4}^{2}$

$Y=558,2422-4,22303 x_{1}+0,01815 x_{1}^{2}-35,30614 x_{2}-$ $0,047395 x_{1} x_{2}+1,08273 x_{2}^{2}-52,56648 x_{3}+0,03140 x_{1} x_{3}$ $+2,04885 x_{2} x_{3}+0,92241 x_{3}^{2}-5,5546 x_{4}+0,04895 x_{1} x_{4}+$ $0,13626 x_{2} x_{4}+0,31732 x_{3} x_{4}+0,013417 x_{4}^{2}$

Table 3

Decolorization efficiency of Cyan dye aqueous solution within the CCD model

\begin{tabular}{|c|c|c|c|c|c|c|}
\hline \multirow{2}{*}{ Sample } & \multicolumn{3}{|c|}{ 1h - Precipitation } & \multicolumn{3}{|c|}{$24 \mathrm{~h}$ - Precipitation } \\
\hline & $A_{0}$ & A & $E_{1 h}(\%)$ & $\mathrm{A}_{0}$ & A & $E_{24 h}(\%)$ \\
\hline 1 & 62.71 & 48.19 & 23.15 & 88.67 & 24.71 & 72.13 \\
\hline 2 & 43.75 & 38.82 & 11.27 & 41.8 & 28.8 & 31.10 \\
\hline 3 & 31.08 & 30.59 & 1.58 & 29.61 & 28.94 & 2.26 \\
\hline 4 & 0.1267 & 0.0694 & 45.22 & 0.069 & 0.0079 & 88.55 \\
\hline 5 & 4.38 & 3.62 & 17.35 & 57.67 & 30.87 & 46.47 \\
\hline 6 & 43.75 & 37.27 & 14.81 & 41.8 & 26.24 & 37.22 \\
\hline 7 & 43.75 & 37.16 & 15.06 & 41.8 & 28.76 & 31.20 \\
\hline 8 & 0.1267 & 0.1028 & 18.86 & 0.069 & 0.0305 & 55.80 \\
\hline 9 & 0.86 & 0.67 & 22.09 & 0.5387 & 0.2805 & 47.93 \\
\hline 10 & 0.1244 & 0.1144 & 8.04 & 0.0467 & 0.0254 & 45.61 \\
\hline 11 & 0.4262 & 0.1875 & 56.01 & 0.4353 & 0.0789 & 81.87 \\
\hline 12 & 43.75 & 36.62 & 16.30 & 41.8 & 30.39 & 27.30 \\
\hline 13 & 33.04 & 10.55 & 68.07 & 28.33 & 7.67 & 72.93 \\
\hline 14 & 28.95 & 28.48 & 1.62 & 29.66 & 28.98 & 2.29 \\
\hline 15 & 4.38 & 4.17 & 4.79 & 57.67 & 54.2 & 6.02 \\
\hline 16 & 46.61 & 45.16 & 3.11 & 61.34 & 44.24 & 27.88 \\
\hline 17 & 28.95 & 21.06 & 27.25 & 29.66 & 16.94 & 42.89 \\
\hline 18 & 10.95 & 6.29 & 42.56 & 12.31 & 6.18 & 49.80 \\
\hline 19 & 0.86 & 0.718 & 16.51 & 0.5387 & 0.2911 & 45.96 \\
\hline 20 & 73.58 & 45.19 & 38.58 & 61.79 & 9.089 & 85.29 \\
\hline 21 & 25.76 & 23.18 & 10.02 & 23.67 & 20.36 & 13.98 \\
\hline 22 & 73.58 & 67.92 & 7.69 & 61.79 & 6.32 & 89.77 \\
\hline 23 & 0.1897 & 0.1588 & 16.29 & 0.0780 & 0.0164 & 78.97 \\
\hline 24 & 0.1897 & 0.1681 & 11.39 & 0.078 & 0.0352 & 54.87 \\
\hline 25 & 0.4262 & 0.1104 & 74.10 & 0.4353 & 0.0159 & 96.35 \\
\hline 26 & 43.75 & 37.32 & 14.70 & 41.8 & 32.19 & 22.99 \\
\hline 27 & 43.75 & 36.66 & 16.21 & 41.8 & 30.04 & 28.13 \\
\hline 28 & 31.08 & 29.05 & 6.53 & 29.61 & 12.66 & 57.24 \\
\hline 29 & 43.75 & 36.35 & 16.91 & 41.8 & 28.28 & 32.34 \\
\hline
\end{tabular}

The statistical significance and adequacy of the quadratic model were analyzed using the analysis of variance (ANOVA), and the results are shown in the tables $4-7$.

The quality of the developed model can be estimated on the basis of several descriptive factors: coefficient of determination $\left(R^{2}\right)$, the P-value, the F-value, as well as the degrees of freedom. The values of $R^{2}$ for the decolorization efficiency after $1 \mathrm{~h}$ and $24 \mathrm{~h}$ of precipitation were 0.704 and 0.732 , respectively, pointing to the medium correlation of the response in the investigated range within the selected model. The obtained result indicates 
that $70 \%$ and $73 \%$ of the variance for the Cyan removal efficiency are explained by an independent variable, and the rest of the total variance (30\% and $27 \%$ ) is not covered by the model. In addition, P-value in the case of $24 \mathrm{~h}$ precipitation was less than 0.05 , which confirms the statistical significance of the applied model.

\section{Table 4}

Regression coefficient after $1 \mathrm{~h}$ precipitation

\begin{tabular}{c|c|c|c|c}
\hline Variables & Coefficient & $\begin{array}{c}\text { Standard } \\
\text { error }\end{array}$ & $\mathbf{T}_{\text {stat }}$ & $\mathbf{P}$ \\
\hline 1 & 378.892 & 88.033 & 4.304 & $7.279 \times 10^{-4}$ \\
\hline $\mathrm{X}_{1}$ & -3.871 & 2.345 & -1.651 & 0.121 \\
\hline $\mathrm{X}_{2}$ & -19.198 & 7.936 & -2.419 & $\mathbf{0 . 0 3 0}$ \\
\hline $\mathrm{X}_{3}$ & -26.200 & 12.287 & -2.132 & $\mathbf{0 . 0 5 2}$ \\
\hline $\mathrm{X}_{4}$ & -4.950 & 1.229 & -4.029 & $\mathbf{0 . 0 0 1}$ \\
\hline $\mathrm{X}_{1} \mathrm{X}_{2}$ & $-2.916 \times 10^{-4}$ & 0.122 & -0.002 & 0.998 \\
\hline $\mathrm{X}_{1} \mathrm{X}_{3}$ & 0.259 & 0.183 & 1.416 & 0.179 \\
\hline $\mathrm{X}_{1} \mathrm{X}_{4}$ & 0.037 & 0.018 & 2.038 & 0.061 \\
\hline $\mathrm{X}_{2} \mathrm{X}_{3}$ & 0.901 & 0.609 & 1.480 & 0.161 \\
\hline $\mathrm{X}_{2} \mathrm{X}_{4}$ & 0.084 & 0.060 & 1.374 & 0.191 \\
\hline $\mathrm{X}_{3} \mathrm{X}_{4}$ & 0.270 & 0.913 & 2.956 & $\mathbf{0 . 0 1 0}$ \\
\hline $\mathrm{X}_{1}^{2}$ & 0.002 & 0.029 & 0.054 & 0.958 \\
\hline $\mathrm{X}_{2}^{2}$ & 0.494 & 0.319 & 1.550 & 0.143 \\
\hline $\mathrm{X}_{3}^{2}$ & -0.593 & 0.717 & -0.826 & 0.422 \\
\hline $\mathrm{X}_{4}^{2}$ & 0.015 & 0.007 & 2.090 & 0.055 \\
\hline
\end{tabular}

\section{Table 5}

Analysis of variance (1h precipitation)

\begin{tabular}{c|c|c|c|c|c}
\hline \multirow{2}{*}{ Model } & $\begin{array}{c}\text { Degrees of } \\
\text { freedom }\end{array}$ & $\begin{array}{c}\text { Sum of } \\
\text { sqare }\end{array}$ & $\begin{array}{c}\text { Mean } \\
\text { square }\end{array}$ & F & P \\
\cline { 2 - 5 } & 14 & 7098.33 & 507.024 & 2.37 & 0.06 \\
\hline Error & 14 & 2990.81 & 213.629 & & \multicolumn{2}{|c}{} \\
\hline Total & 28 & 10089.1 & \multicolumn{1}{|c}{} \\
\cline { 1 - 4 }
\end{tabular}

\section{Table 6}

Regression coefficient after $24 \mathrm{~h}$ precipitation

\begin{tabular}{c|c|c|c|c}
\hline Variables & Coefficient & $\begin{array}{c}\text { Standard } \\
\text { error }\end{array}$ & $\mathbf{T}_{\text {stat }}$ & $\mathbf{P}$ \\
\hline 1 & 558.242 & 119.387 & 4.676 & $\mathbf{3 . 5 7 1 \times \mathbf { 1 0 }}$ \\
\hline$X_{1}$ & -4.223 & 3.180 & -1.328 & 0.205 \\
\hline$X_{2}$ & -35.306 & 10.763 & 3.280 & $\mathbf{0 . 0 0 5}$ \\
\hline$X_{3}$ & -52.567 & 16.663 & -3.155 & $\mathbf{0 . 0 0 7}$ \\
\hline$X_{4}$ & -5.554 & 1.666 & -3.333 & $\mathbf{0 . 0 0 5}$ \\
\hline$X_{1} X_{2}$ & -0.047 & 0.165 & -0.287 & 0.778 \\
\hline$X_{1} X_{3}$ & 0.031 & 0.248 & 0.128 & 0.901 \\
\hline$X_{1} X_{4}$ & 0.049 & 0.0248 & 1.976 & 0.068 \\
\hline$X_{2} X_{3}$ & 2.049 & 0.826 & 2.481 & $\mathbf{0 . 0 2 6}$ \\
\hline$X_{2} X_{4}$ & 0.136 & 0.083 & 1.650 & 0.121 \\
\hline$X_{3} X_{4}$ & 0.317 & 0.124 & 2.561 & $\mathbf{0 . 0 2 3}$ \\
\hline$X_{1}^{2}$ & 0.018 & 0.039 & 0.467 & 0.648 \\
\hline$X_{2}^{2}$ & 1.083 & 0.432 & 2.504 & $\mathbf{0 . 0 2 5}$ \\
\hline$X_{3}^{2}$ & 0.922 & 0.973 & 0.948 & 0.359 \\
\hline$X_{4}^{2}$ & 0.013 & 0.010 & 1.379 & 0.189 \\
\hline & & & &
\end{tabular}

\section{Table 7}

Analysis of variance (24h precipitation)

\begin{tabular}{c|c|c|c|c|c}
\hline \multirow{2}{*}{ Model } & $\begin{array}{c}\text { Degrees of } \\
\text { freedom }\end{array}$ & $\begin{array}{c}\text { Sum of } \\
\text { sqare }\end{array}$ & $\begin{array}{c}\text { Mean } \\
\text { square }\end{array}$ & F & P \\
\cline { 2 - 6 } & 14 & 15036.1 & 1074.01 & 2.73 & 0.35 \\
\hline Error & 14 & 5500.61 & 932.90 & \multicolumn{2}{|c}{} \\
\hline Total & 28 & 20536.7 & \multicolumn{1}{|c}{} \\
\cline { 1 - 4 }
\end{tabular}

The actual and predicted values for the Cyan dye removal efficiency from the aqueous solution after $1 \mathrm{~h}$ and $24 \mathrm{~h}$ of precipitation are presented in Figure 3. It can be concluded that calculated values by the predictive model are not in a satisfactory correlation with the experimentally obtained values, which is confirmed by the weak correlation between the observed values.
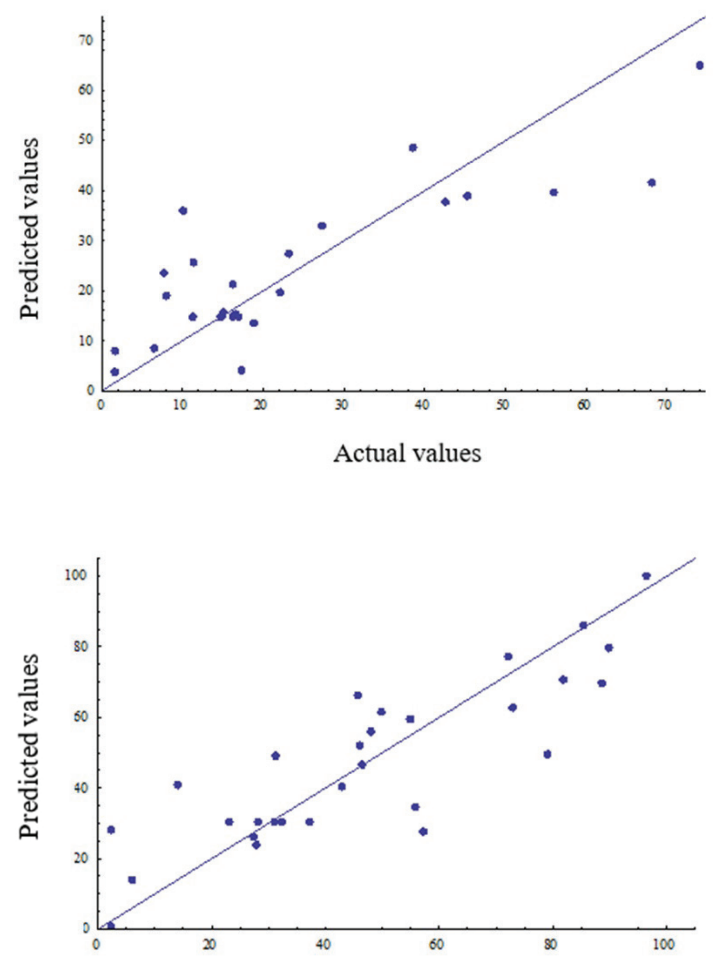

Actual values

» Figure 3: Comparison of predicted and obtained values of the decolorization efficiency of Cyan dye aqueous solution for: a) $1 \mathrm{~h}$ and b) $24 \mathrm{~h}$ precipitation

The analysis of variance, as a statistical method, indicates which independent variable has a significant influence on the dependent variable through the Fischer statistical test. The F-test was used to estimate the statistical significance of each expression in a polynomial equation within the confidence interval of $95 \%$. The values of $F$ parameter of 2.373 and 2.733 are higher than tabular value, indicating the model significance. Based on the obtained P-value for each analyzed parameter, it can be concluded which parameters are statistically significant and which of them plays an important role in the Cyan decolorization process. The values of P-parameter lower 
than confidence interval of 0.005 indicate the existence of statistical significance, and vice versa, the P-values higher than 0.100 indicate the fact that the investigated parameter is not statistically significant. Therefore, it can be concluded that in the case of Cyan dye removal after $1 \mathrm{~h}$ of precipitation, the greatest influence is achieved by the initial dye concentration and removal time, as well as the interaction between $\mathrm{pH}$ value and the removal time. In the case of $24 \mathrm{~h}$ precipitation, it has been determined that the initial dye concentration, $\mathrm{pH}$ value, removal time, and interaction between dye concentration and the reaction time, as well as the $\mathrm{pH}$ and reaction time interactions are determined to have the greatest effect on the decolorization process.

Based on the analyzed results, it can be concluded that linear factors are predominantly statistically sig-

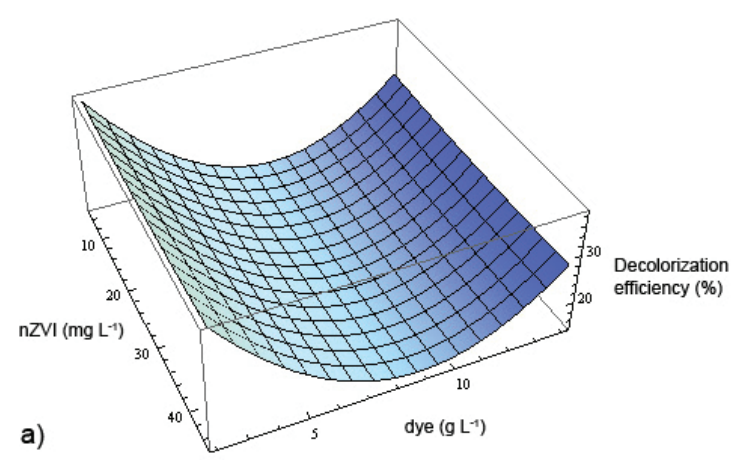

c)


nificant, as well as two square factors (reaction time for $1 \mathrm{~h}$ precipitation and dye concentration for $24 \mathrm{~h}$ precipitation), which confirms the lower value of the coefficient of determination. However, the linear and cubic model did not satisfy the given criteria, due to the lower values of the descriptive factors, and the results are interpreted through a quadratic model.

Software Wolfram Mathematica 8 was used to construct three-dimensional (3D) regression surfaces, a graphic representation of the regression equation for optimizing the reaction conditions, as a reliable approach in defining the condition of the reaction system (Figures 4 and 5). The 3D graphs indicate the response function of the two factors, while the other two factors are fixed, and the selected regression surfaces represent the Central points of the experiment.

b)

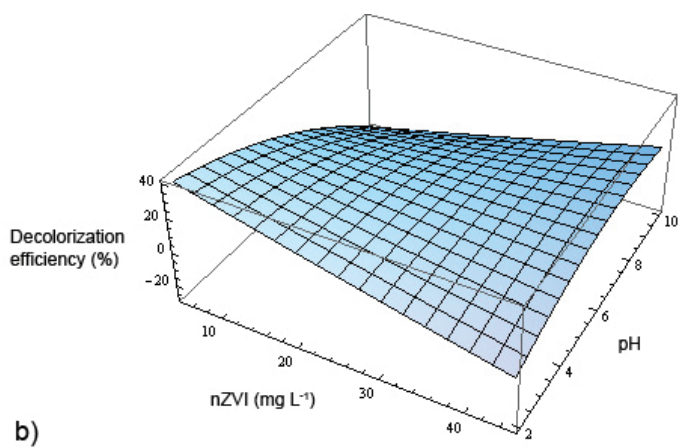

d)
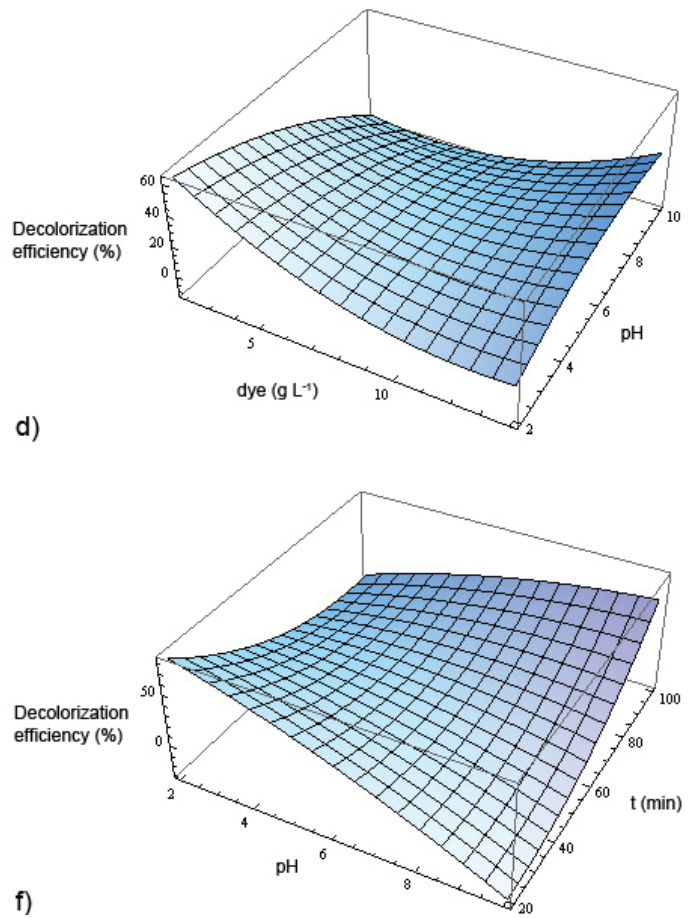

» Figure 4: Regression 3D surfaces of decolorization efficiency after 1 h precipitation in function of: a) nZVI dosage and dye concentration; b) nZVI dosage and $p H$; c) nZVI dosage and the removal time; d) dye concentration and pH; e) dye concentration and removal time; f) $\mathrm{pH}$ value and removal times 



d)

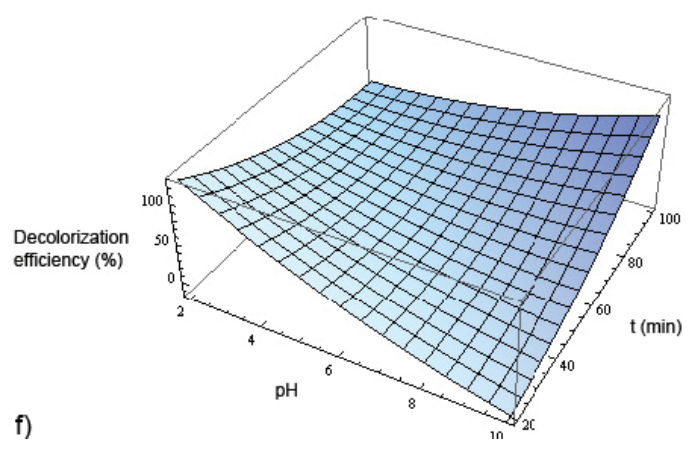

» Figure 5: Regression 3D surfaces of decolorization efficiency after 24h precipitation in function of: a) nZVI dosage and dye concentration; b) nZVI dosage and $\mathrm{pH}$; c) nZVI dosage and the removal time; d) dye concentration and $p H$; e) dye concentration and removal time; f) $\mathrm{pH}$ value and removal times

The initial dye concentration has a significant effect on the decolorization efficiency. It has been found that with the increase of dye concentration the decolorization efficiency decreases (Figures 4 and $5 \mathrm{~d}$-e). This further points to the fact that reductive degradation is weak, due to the low nZVI dosage applied in order to remove large dye concentrations. Additionally, at lower dye concentrations, a close relationship is established between the added nanomaterial and the dye molecule. Beside reaction time, which had the greatest influence on the dye removal process from the aqueous solution, $\mathrm{pH}$ value represents a significant parameter in the experiment. As it is obvious from Figures 4 and 5 (b, $c$ and f) Cyan removal increased at strong acidic range and decreased at extremely basic conditions. The effect of $\mathrm{pH}$ significance is explained by the discharge of the dye molecules, which is most evident at low $\mathrm{pH}$ values between 2 and 4 . As confirmed by the results of the ANOVA test, the nZVI dosage has the lowest influence in the Cyan degradation, whereby from the Figure 4 and $5(\mathrm{a}-\mathrm{c})$ is noticeable that when $\mathrm{nZVI}$ concentration increase, the decolorization efficiency is reduced. This confirms the fact that the dye molecules are not sorbed on the nanomaterial surface, but under the influence of the change in the $\mathrm{pH}$, they are transferred from liquid to solid phase, forming a certain quantity of sludge (Figure 6) which requires further treatment after separation from a colorless solution.

\section{Conclusion}

Iron nanoparticles, synthesized by "green" method from oak leaves, appeared to be an active catalyst for removal of Cyan flexo dye from aqueous solution. A CCD, followed by analysis of variance, was applied to optimize experimental conditions for dye removal. According to the analysis results, $\mathrm{nZVI}$ dosage $\left(5 / 45 \mathrm{mg} \mathrm{L}^{-1}\right)$, removal 

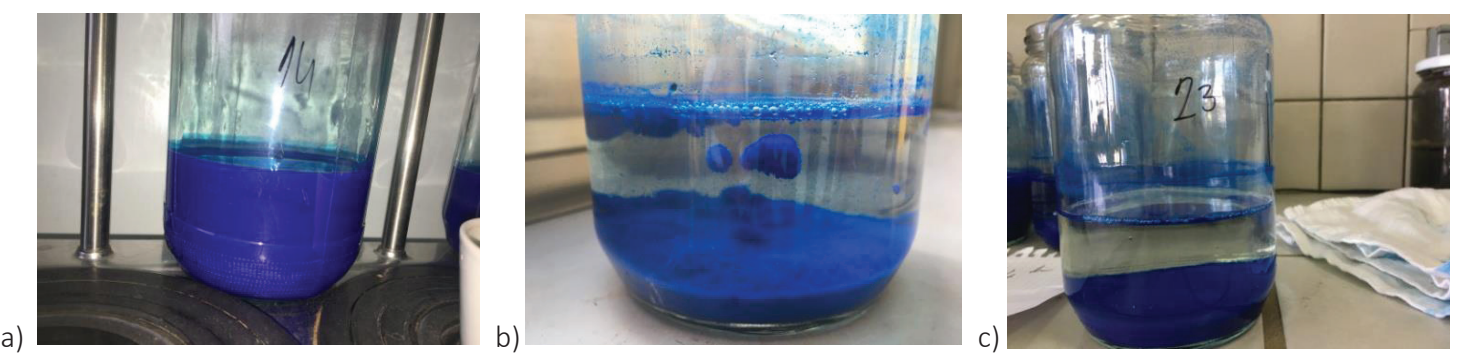

" Figure 6: a) Aqueous solution of Cyan dye before treatment; b) Aqueous solution of Cyan dye after treatment and Thour precipitation c) Aqueous solution of Cyan dye after treatment and $24 \mathrm{~h}$ precipitation

time (20/100 $\mathrm{min}), \mathrm{pH}(2 / 10)$ and initial concentration $\left(2 / 14 \mathrm{~g} \mathrm{~L}^{-1}\right)$ of Cyan dye formed the optimum conditions. In the present study, initial Cyan concentration, $\mathrm{pH}$ value and reaction time achived the most significant influence on the decolorization efficiency. Results show that the removal of Cyan dye increases with the increase of the $\mathrm{nZVI}$ dosage and removal time, as well as with the decrease of $\mathrm{pH}$ value and initial dye concentration. It was established that organic compound in the aqueous solution cannot be degraded completely by the applied process and as a result, the total cost can increase because of the need for further treatment. However, the model validation results $\left(R^{2}=0.704\right.$ and 0.732$)$ indicated the moderate adequacy of the developed model, whereas the analysis of variance depicts the accuracy of the model by using high F-value (2.373 and 2.733), and very low P-value $(<0.005)$. Based on the obtained results, it can be concluded that RSM is one of the most useful methods to optimize the experimental conditions for the removal of Cyan dye from wastewater. However, the organic compound in the aqueous solution cannot be degraded completely by the applied process. In order to increase decolorization efficiency, implementation of other processes and additional optimization parameters is required.

\section{Acknowledgements}

The authors acknowledge the financial support of the Ministry of Education, Science and Technological Development of the Republic of Serbia within the Projects No. TR 34014 and III43005.

\section{References}

Adamović, S., Prica, M., Radonić, J., Turk Sekulić, M. \& Pap, S. (2014) Safety evaluation of the leaching of metals from the printed graphic product wastes. Journal of Graphic engineering and design. 5 (2), 9-15. Available from: http://www.grid.uns.ac.rs/jged/download. php?fid=146 [Accessed 15th September 2017].

Andrade, C., Miguez, G., Gomez, T. \& Bugallo B. (2012) Management strategy for hazardous waste from atomised SME: application to the printing industry. Journal of Cleaner Production.
35, 214-229. Available from: doi: 10.1016/j.jclepro.2012.05.014 [Accessed 15th September 2017].

Asfaram, A., Ghaedi, M., Hajati, S., Goudarzi, A. \& Bazrafshan, A. (2015) Simultaneous ultrasound-assisted ternary adsorption of dyes onto copper-doped zinc sulfide nanoparticles loaded on activated carbon: Optimization by response surface methodology. Spectrochimica Acta Part A: Molecular and Biomolecular Spectroscop. 145, 203-212. Available from: doi: 10.1016/j. saa.2015.03.006 [Accessed 15th September 2017]. De Sales, P., Magriotis, Z., Rossi, M., Resende, R. \& Nunes, C. (2013) Optimization by Response Surface Methodology of the adsorption of Coomassie Blue dye on natural and acid-treated clays. Journal of Environmental Management. 130, 417-428. Available from: doi: 10.1016/j.jenvman.2013.08.067. [Accessed 18th September 2017].

Dutta, S., Saha, R., Kalita, H. \& Bezbaruah, A.

(2015) Rapid reductive degradation of azo and anthraquinone dyes by nanoscale zero-valent iron. Environmental Technology \& Innovation. 5, 176-187. Available from: doi: 10.1016/j. eti.2016.03.001. [Accessed 18th September 2017]. Elhalil, A., Tounsadi, H., Elmoubarki, R., Mahjoubi, F.Z., Farnane, M., Sadiq, M., Abdennouri, M., Qourzal, S. \& Barka, N. (2016) Factorial experimental design for the optimization of catalytic degradation of malachite green dye in aqueous solution by Fenton process. Water Resources and Industry. 15, 41-48. Available from: doi: 10.1016/j. wri.2016.07.002. [Accessed 18th September 2017].

Haddad, M., Regti, A., Laamari, M., Mamouni, R. \& Saffaj, R. (2014) Use of Fenton reagent as advanced oxidative process for removing textile dyes from aqueous solutions. Journal of Materials and Environmental Science. 5 (3), 667-674. Available from: https://www.jmaterenvironsci.com/Document/vol5/vol5_N3/82-JMES-5942014-ElHaddad.pdf [Accessed 24th September 2017]. Kerez, Dj., Tomašević, D., Kozma, G., Bečelić-Tomin, M., Prica, M., Rončević, S., Kukovecz, A., Dalmacija, B. \& Konya, Z. (2014) Three different clay-supported nanoscale zero-valent iron materials for industrial azo dye degradation: A comparative study. Journal of the Taiwan Institute of Chemical Engineers. 
45, 2451-2461. Available from: doi: 10.1016/j. jtice.2014.04.019 [Accessed 24th September 2017].

Khan, M., Ahmad, A., Bangash, F., Shan, S. \& Khan, P. (2013) Removal of Basic Dye from Aqueous Solutions Using Nano Scale Zero Valent Iron (nZVI) as Adsorbent. Journal of Chemical Society Pakistan. 35 (3), 744-748. Available from: http://tiny. cc/aghcpy [Accessed 26th September 2017].

Kiurski, J., Marić, B., Aksentijević, S., Oros, I. \& Kecić, V. (2016) Occupational hazards in printing industry. International Journal of Environmental Science and Technology. 13 (3), 955-972. Available from: doi: 10.1007/ s13762-016-0937-z [Accessed 27th September 2017].

Longman, A., Bali, B., Lutzenkirchen, J., Weidler, P. \& Kherbech, A (2016) Adsorptive removal of crystal violet dye by a local clay and process optimization by response surface methodology. Applied Water Science. 7 (7), 3649-3660. Available from: doi: 10.1007/ s13201-016-0509-x [Accessed 27th September 2017].

Machado, S., Pinto, S., Grosso, J., Nouws, H., Albergaria, J. \& Delerue-Matos, C. (2013) Green production of zero-valent iron nanoparticles using tree leaf extracts. Science of the Total Environment. 445-446, 1-8. Available from: doi: 10.1016/j.scitotenv.2012.12.033 [Accessed 28th September 2017].

Markandeya, A., Dhiman, N., Shukla, S. \& Kisku, G. (2017) Statistical optimization of process parameters for removal of dyes from wastewater on chitosan cenospheres nanocomposite using response surface methodology. Journal of Cleaner Production. 149, 597-606. Available from: doi: 10.1016/j.jclepro.2017.02.078 [Accessed 28th September 2017].

Mijin, D. (2012) Printing dyes and adhezives. [Grafičke boje i lepkovi]. University of Belgrade, Faculty of Technology and Metallurgy. Available from: http://www.dusanmijin.in.rs/ GBL.pdf [Accessed 29th September 2017].

Nayana, H. \& Pushpa, T. (2016) Nano Zero-valent Iron for the Removal of Color and Chemical Oxygen Demand of Textile Effluent. Indian Journal of Advances in Chemical Science. 1, 236-238. Available from: http://www.ijacskros.com/artcles/ IJACS-2S-49.pdf [Accessed 1st October 2017].

O'Carroll, D., Sleep, B., Krol, M., Boparai, H. \& Kocur, C. (2013) Nanoscale zero valent iron and bimetallic. Advances in Water Resources. 51, 104-122. Available from: doi: 10.1016/j. advwatres.2012.02.005 [Accessed 1st October 2017].

Poguberović, S. (2016) Metal removal from water by using stabilized and green synthesis produced nano iron. [Uklanjanje metala iz vode primenom stabilisanog $i$ „zelenom” sintezom produkovanog nano gvožđa (O)], PhD thesis. Faculty of Science, University of Novi Sad. Available from: https://www.google. $r s /$ rl? sa $=$ t\&rct=j\&q=\&esrc=s\&source=web\&c $\mathrm{d}=4 \&$ ved=0ahUKEwjCodeqk4nYAhWBmbQKHUPQAF0QFgg8MAM\&url=http\%3A\%2F\%2Fnardus.mpn.gov. rs\%2Fbitstream\%2Fhandle\%2F123456789\%2F6294\%2F-
Disertacija4246.pdf\%3Fsequence\%3D1\%26isAllowed\%3Dy\&usg=AOvVaw2uJYswP-xvdHnxzLj2ylia [Accessed 3th October 2017].

Poguberović, S., Krčmar, D., Maletić, S., Konya, Z., Tomašević Pilipović, D., Kerkez, Đ. \& Rončević, S. (2016) Removal of As(III) and Cr(VI) from aqueous solutions using "green" zero-valent iron nanoparticles produced by oak, mulberry and cherry leaf extracts. Ecological Engineering. 90, 42-49. Available from: doi: 10.1016/j.ecoleng.2016.01.083 [Accessed 3th October 2017].

Poursaberi, T., Hassanisadi, M. \& Nourmohammadian, F. (2012) Application of Synthesized Nanoscale Zero-Valent Iron in the Treatment of Dye Solution Containing Basic Yellow 28. Progress in Color, Colorants and Coatings Journal. 5, 35-40. Available from: http:// www.cecst.irancolorinstitute.com/Folders/CECSTEN02Nour01.pdf [Accessed 4th October 2017].

Rakshaee, R. (2011) Rule of $\mathrm{Fe}^{0}$ nano-particles and biopolymer structures in kinds of the connected pairs to remove Acid Yellow 17 from aqueous solution: Simultaneous removal of dye in two paths and by four mechanisms. Journal of Hazardous Materials. 197, 144-152. Available from: doi: 10.1016/j. jhazmat.2011.09.067 [Accessed 4th October 2017].

Raman, C. \& Kanami, S. (2016) Textile dye degradation using nano zero valent iron: A review. Journal of Environmental Mangement. 177, 341-355. Available from: doi: 10.1016/j.jenvman.2016.04.034 [Accessed 4th October 2017].

Rasouli, Y., Abbasi, M. \& Hashemifard, S.A. (2017) Investigation of in-line coagulation-MF hybrid process for oily wastewater treatment by using novel ceramic membranes. Journal of Cleaner Production. 161, 545-559. Available from: doi: 10.1016/j. jclepro.2017.05.134 [Accessed 4th October 2017].

Saad, M., Tahir, H., Khan, J., Hameed, U. \& Saud, A (2017) Synthesis of polyaniline nanoparticles and their application for the removal of Crystal Violet dye by ultrasonicated adsorption process based on Response Surface Methodology. Ultrasonics Sonochemistry. 34, 600-608. Available from: doi: 10.1016/j.ultsonch.2016.06.022 [Accessed 5th October 2017].

Saif, S., Tahir, A. \& Chen., Y. (2016) Green Synthesis of Iron Nanoparticles and Their Environmental Applications and Implications. Nanomaterials (Basel). 6(11), 209-215. Available from: doi: 10.3390/ nano6110209 [Accessed 5th October 2017].

Satapnajaru, T., Chompuchan, C., Suntornchot, P. \& Pengthamkeerat, P. (2011) Enhancing decolorization of Reactive Black 5 and Reactive Red 198 during nano zerovalent iron treatment. Desalination. 266(1-3), 218-230. Available from: doi: 10.1016/j. desal.2010.08.030 [Accessed 8th October 2017].

Wu, H. \& Wang, S. (2012) Impacts of operating parameters on oxidation-reduction potential and pretreatment efficacy in the pretreatment of printing and dyeing wastewater by 
Fenton process. Journal of Hazardous Materials. (243), 86-94. Available from: doi: 10.1016/j. jhazmat.2012.10.030 [Accessed 8th October 2017].

Yari, A., Nazari, S., Rastegar, A., Alizadeh-Matboo, S., Majidi, G. \& Tahaye-Reshvanloo, M. (2015) Removal of Acid Red 18 dye from Aqueous Solutions Using Nanoscale Zero-Valent Iron. Iranian Journal of Health Sciences. 3(3), 63-69. Available from: doi: 10.7508/ ijhs.2015.03.008 [Accessed 8th October 2017].

Zou, Y., Wang, X., Khan, A., Wang, P., Liu, Y., Alsaedi, A., Hayat, T. \& Wang, X. (2016) Environmental Remediation and Application of Nanoscale Zero-Valent Iron and Its Composites for the Removal of Heavy Metal Ions: A Review. Environmental Science and Technology. 50 (14), 7290-7304. Available from: doi: 10.1021/ acs.est.6b01897 [Accessed 11th October 2017].

Znao, Z., Liu, J., Tai, C., Zhou, Q., Hu, J. \& Jiang, G. (2008) Rapid decolorization of water soluble azo-dyes by nanosized zero-valent iron immobilized on the exchange resin. Science in China Series B: Chemistry. 51 (2), 186-192. Available from: doi: 10.1007/ s11426-007-0121-x [Accessed 13th October 2017].



(C) 2017 Authors. Published by the University of Novi Sad, Faculty of Technical Sciences, Department of Graphic Engineering and Design. This article is an open access article distributed under the terms and conditions of the Creative Commons Attribution license 3.0 Serbia (http://creativecommons.org/licenses/by/3.0/rs/). 